\title{
Aleitamento materno, amamentação tranquila e prazerosa: um relato de experiência
} Breastfeeding, peaceful and pleasant breastfeeding: an experience report Lactancia materna, lactancia pacífica y placentera: un informe de experiencia

Recebido: 27/04/2020 | Revisado: 27/04/2020 | Aceito: 29/04/2020 | Publicado: 05/05/2020

Eyshila Marilia Almeida Rocha

ORCID: https://orcid.org/0000-0002-5054-2508

Universidade Estadual do Maranhão, Brasil

E-mail: eyshilamarilia@hotmail.com

Lawanda Kelly Matias de Macedo

ORCID: https://orcid.org/0000-0001-5456-052X

Universidade Estadual do Maranhão, Brasil

E-mail: lawandak360@gmail.com

\section{Layla Valéria Araújo Borges}

ORCID: https://orcid.org/0000-0002-4715-407X

Universidade Estadual do Maranhão, Brasil

E-mail: laylavaleria25@gmail.com

Aline Maria da Costa Pinheiro

ORCID: https://orcid.org/0000-0002-2292-8999

Universidade Estadual do Maranhão, Brasil

E-mail: aline28pinheiro@gmail.com

Rosielly da Silva Santos

ORCID: https://orcid.org/0000-0002-0196-3525

Universidade Estadual do Maranhão, Brasil

E-mail: rosielly.silva773@gmail.com

Hayla Nunes da Conceição

ORCID: http://orcid.org/0000-0001-6035-8280

Universidade Federal do Piauí, Brasil

E-mail: haylanunes_cx@hotmail.com

Joseneide Teixeira Câmara

ORCID: https://orcid.org/0000-0002-8312-1697 
Universidade Estadual do Maranhão, Brasil E-mail: josaeneide.tc@gmail.com

\title{
Resumo
}

Objetivo: Relatar as experiências de ações educativas vividas durante atividades de extensão sobre aleitamento materno e amamentação realizadas em uma Maternidade. Além de evidenciar a importância da amamentação e de suas técnicas corretas. Métodos: Trata-se de um estudo descritivo, do tipo relato de experiência obtido a partir de vivências de um projeto de extensão realizado com puérperas no período de novembro de 2019 a fevereiro de 2020, em uma Maternidade localizada em um município do interior do Maranhão. Resultados: Durante o período de atividades, as puérperas foram orientadas a respeito da importância do aleitamento materno e técnicas corretas para que o mesmo pudesse ocorrer de forma segura e prazerosa. Conclusão: É necessário que a mulher esteja segura e bem informada a respeito do manejo correto do aleitamento. Assim, todos os benefícios que a amamentação proporciona tanto para a mãe quanto para o bebê poderão ser alcançados.

Palavras-chave: Aleitamento materno; Alojamento conjunto; Enfermagem materno-infantil.

\begin{abstract}
Objective: To report the experiences of educational actions lived during activities of extension about breastfeeding and breastfeeding carried out in a Maternity s. In addition to highlighting the importance of breastfeeding and its correct techniques. Methods: This is a descriptive study, of the experience report type obtained from the experiences of an extension project carried out with puerperal women in the period from November 2019 to February 2020, in a maternity hospital located in a municipality in the interior of Maranhão. Results: During the period of activities, the mothers were instructed about the importance of breastfeeding and correct techniques so that it could occur in a safe and pleasant way. Conclusion: It is necessary that the woman is safe and well informed about the correct management of breastfeeding. Thus, all the benefits that breastfeeding provides for both mother and baby can be achieved.
\end{abstract}

Key words: Breast Feeding; Rooming-in Care; Maternal-Child Nursing.

\section{Resumen}

Objetivo: Informar las experiencias de acciones educativas vividas durante actividades de extensión sobre lactancia materna y lactancia materna realizadas en una Maternidad. Además de resaltar la importancia de la lactancia materna y sus técnicas correctas. Métodos: Este es 
un estudio descriptivo, un tipo de informe de experiencia obtenido de las experiencias de un proyecto de extensión realizado con mujeres puerperales en el período comprendido entre noviembre de 2019 y febrero de 2020, en un hospital de maternidad ubicado en un municipio en el interior de Maranhão. Resultados: Durante el período de actividades, las madres fueron instruidas sobre la importancia de la lactancia materna y las técnicas correctas para que pueda ocurrir de una manera segura y placentera. Conclusión: es necesario que la mujer esté segura y bien informada sobre el manejo correcto de la lactancia materna. Por lo tanto, se pueden lograr todos los beneficios que la lactancia materna brinda tanto a la madre como al bebé.

Palabras clave: Lactancia Materna; Alojamiento Conjunto; Enfermería Maternoinfantil.

\section{Introdução}

Durante toda a sua existência a humanidade pôde contar com a amamentação. O aleitamento materno (AM) é uma fonte ideal de nutrição onde encontra-se as quantidades adequadas de substâncias indispensáveis para o desenvolvimento do lactente: água, carboidratos, proteínas e lipídeos (Nunes, 2015). Até os doze meses de vida o leite supre cerca de $75 \%$ das proteínas que a criança necessita. Adicionalmente também são encontrados outros componentes, tais como: açúcar, vitaminas, gorduras e sais minerais (Margotti \& Margotti, 2017).

O aleitamento proporciona uma ligação afetiva entre mãe e bebê e está relacionado à proteção imunológica e diminuição do risco de câncer de mama nas mães, sendo uma maneira de economizar os gastos da família com alimentação da criança (Ibidem, 2017). Estudos evidenciam os efeitos positivos no desenvolvimento intelectual, desempenho escolar e renda, quando na idade adulta (Toriyama, et al., 2017). Embora os benefícios sejam conhecidos, vários fatores podem levar à interrupção precoce da amamentação e, ainda que a importância do AM e seus benefícios sejam inquestionáveis, o emprego da amamentação e a dissipação de informação sobre o tema não ocorre de forma adequada, contribuindo, assim, para sua interrupção realizar-se cada vez mais cedo (Gonçalves, 2016).

É de fundamental importância, que haja acompanhamento e aconselhamento adequado durante todo o período de pré-natal, perinatal e pós-natal com intuito de levar informações, orientações e esclarecimentos relacionados à prática da amamentação, adequar seus comportamentos posturais e as dificuldades iniciais de forma correta afim de promover saúde e evitar o desmame precoce (Alves, et al., 2018). 
A ação de lactar sofre influência do meio social em que a gestante está inserida, por isso é importante que os profissionais de saúde a orientem para combater possíveis mitos, tabus e práticas que podem trazer prejuízos à amamentação (Algarves, Julião \& Costa, 2015). Nesse sentido, o presente estudo tem como objetivo relatar experiências de ações educativas de extensão sobre aleitamento materno e amamentação realizadas em uma Maternidade e evidenciar a importância da amamentação e de suas técnicas corretas.

\section{Metodologia}

Trata-se de um trabalho descritivo do tipo relato de experiência como considera de natureza qualitativa Pereira et al. (2018) e, realizado a partir de atividades de extensão do projeto "Aleitamento Materno: amamentação tranquila e prazerosa" realizado em uma Maternidade localizada no interior do estado do Maranhão, no período de novembro de 2019 a fevereiro de 2020 .

O projeto contou com a participação de cinco acadêmicas de enfermagem da Universidade Estadual do Maranhão, das quais duas cursam o $7^{\circ}$ período e três cursam o $3^{\circ}$ período e, ainda com a participação de uma enfermeira obstetra que trabalha nas dependências da Maternidade e que acompanhou supervisionando e dando apoio em todas as atividades. Estas foram realizadas com puérperas que se encontravam na Maternidade Carmosina Coutinho e abriu-se espaço para a participação de acompanhantes e visitas que estavam presentes nos berçários. Foram confeccionados e utilizados banners e folders educativos contendo textos e imagens, além de dinâmica interativa com objetivo de socializar e fixar os conhecimentos repassados.

A atividade de educação em saúde foi fracionada em três momentos: no primeiro, apresentação do projeto, e por meio do banner, exposição dos benefícios do aleitamento materno para a mãe e bebê e das técnicas essenciais para que o mesmo pudesse ocorrer de forma adequada. Em seguida, realizou-se uma dinâmica denominada "mitos e verdades sobre a amamentação", na qual as puérperas tiveram a oportunidade de sanar algumas dúvidas sobre a temática. E por fim, foi entregue a cada puérpera um folder contendo informações semelhantes às que foram apresentadas anteriormente com o objetivo de fixar ainda mais o conteúdo educativo. Esses três momentos somados, tiveram duração de 20 a 25 minutos. 


\section{Relato de Experiência e Discussão}

As atividades educativas de extensão contaram com 163 puérperas e mais acompanhantes e/ou visitantes. As atividades e vivências do projeto possibilitaram uma conquista e compartilhamento de conhecimentos tanto empírico, quanto científico. A prática de uma amamentação contínua e vantajosa é mais comumente relacionada a mães que estão mais conscientes e empoderadas a respeito dos benefícios do aleitamento (Algarves, Julião \& Costa, 2015).

Percebeu-se que as atividades realizadas tiveram resultados satisfatórios, pois tanto os acadêmicos quanto as puérperas e acompanhantes que participaram do projeto, mesmo que indiretamente, tiveram oportunidade de ampliação dos saberes sobre o aleitamento materno. A utilização da dinâmica no projeto possibilitou uma maior interação e todos puderam participar ativamente questionando sobre o tema, tirando suas dúvidas e compartilhando suas experiências.

A boa comunicação no processo de amamentação é de suma importância, assim como a existência de um vínculo dos profissionais de saúde com as mães e familiares, o que promove a longitudinalidade do cuidado, maior probabilidade de que as orientações sejam seguidas e consequentemente, que os benefícios sejam alcançados (Andrade, Pessoa \& Donizete, 2018). Evidências apontam que a educação em saúde, o auxílio dos profissionais e apoio familiar e social são fatores determinantes para a adesão ao AM, bem como uma prolongação e exclusividade no processo (Nabulsi, et al., 2014)

Durante o período de atividades as puérperas puderam aprender algumas técnicas para amamentar, como por exemplo: posição em que a mãe e a criança devem estar, pega correta do bebê ao seio, como fazer massagem no seio, entre outras. Todas as informações e práticas adequadas que foram repassadas às mães, se seguidas, possibilitam a elas uma lactação segura, tranquila e prazerosa.

Para que haja sucesso no processo de amamentar, faz-se necessário que haja uma pega correta do bebê ao seio e isso inclui alguns determinantes que devem ser checados: posicionamento do binômio mãe-lactente, queixo do bebê tocando o seio, bochechas cheias, lábio inferior voltado para fora, entre outros. Esses fatores contribuem para que haja uma pega correta e assim, se evite possíveis traumas e lesões mamilares que podem trazer dificuldades na amamentação e ainda, desmame precoce (Barbosa, et al., 2018). Além disso, a pega incorreta pode fazer com que o lactente não consiga sugar o leite de forma eficiente, o que pode trazer prejuízo à sua nutrição. Da mesma forma, as fissuras no seio materno podem 
deixar a puérpera ansiosa, estressada e sem autoconfiança, sendo levada a acreditar que o leite que produz é escasso e/ou fraco (Souza, et al., 2016). Nesse sentido, se dá a relevância da existência de atividades educativas que tem por objetivo orientar essas mulheres sobre a temática vigente, empoderá-las e sanar as suas dúvidas para que ela encontre prazer e satisfação no momento de amamentar e também para que o binômio mãe-lactente experimente os benefícios do AM.

\section{Considerações Finais}

O projeto contribuiu na formação profissional dos acadêmicos participantes uma vez que possibilitou a união dos conhecimentos teóricos sob a perspectiva da prática. As orientações transmitidas puderam desvendar muitos mitos adquiridos pelos familiares e puérperas, e estas foram estimuladas a aplicar os conhecimentos em seu cotidiano e transmitir o aprendizado obtido.

Diante desse estudo, verificou-se que as práticas de educação em saúde são fundamentais para que se possam identificar as deficiências e maiores necessidades das puérperas em relação à amamentação, e a partir disso, para que haja a elaboração de estratégias e de intervenções que mudem essa realidade.

\section{Referências}

Algarves, T.R., de Sousa Julião, A.M., \& Costa, H.M. (2015). Aleitamento materno: influência dos mitos e crenças no desmame precoce. Saúde em Foco, 2(1): 151-167. Acesso em 20 abr 2020. Disponível em: http://www4.fsanet.com.br/revista/index.php/saudeemfoco/article/view/912

Alves, D. A., de Carvalho Santos, F., Almeida, L. A., \& Mattos, M. P. (2018). Educação em saúde no processo de posicionamento da mãe com o bebê durante a amamentação. Em Extensão, 16(2): 242-252. Acesso em 20 abr 2020. Disponível em: http://www.seer.ufu.br/index.php/revextensao/article/view/39400

Andrade, H.S., Pessoa, R.A., \& Donizete, L.C.V. (2018). Fatores relacionados ao desmame precoce do aleitamento materno. Revista Brasileira de Medicina, Família e Comunidade, 
13(40):1-11. Acesso em 20 de abr de 2020. Disponível em:

https://rbmfc.org.br/rbmfc/article/view/1698

Barbosa, G.E.F., Pereira, J.M., Soares, M.S., Pereira, L.B., Pinho, L., \& Caldeira, A.P. (2018). Dificuldades iniciais com a técnica da amamentação e fatores associados a problemas com a mama em puérperas. Revista Brasileira de Saúde Materno Infantil, 18 (3): 527-537. Acesso em 20 de abr de 2020. Disponível em:

http://www.scielo.br/scielo.php?script=sci_arttext\&pid=S0103-05822017000300265

Gonçalves, C. C. (2016). Conhecimento sobre aleitamento materno entre puérperas em um hospital do extremo sul do Rio Grande do Sul. Dissertação (Mestrado Profissionalizante em Saúde da Mulher, Criança e Adolescente) - Universidade Católica de Pelotas, Programa de Pós-Graduação. Pelotas. Acesso em 20 de abr de 2020. Disponível em:

http://pos.ucpel.edu.br/mpsmca/wpcontent/uploads/sites/2/2018/03/Disserta\%C3\%A7\%C3\%A3o-Caroline-de-Castro.pdf

Margotti, E., \& Margotti, W. (2017). Fatores relacionados ao Aleitamento Materno Exclusivo em bebês nascidos em hospital amigo da criança em uma capital do Norte brasileiro. Saúde em Debate, 41, 860-871. Acesso em 20 de abr de 2020. Disponível em:

http://www.repositorio.ufpa.br:8080/jspui/handle/2011/10326

Nabulsi, M., Hamadeh, H., Tamim H., Kabakian, T., Charafeddine, G., Yehya, N., Sinno, D., \& Sidani, S. (2014). A complex breastfeeding promotion and support intervention in a developing country: study protocol for a randomized clinical trial. BMC Public Health, 14(36):1-11. Acesso em 20 de abr de 2020. Disponível em:

https://www.ncbi.nlm.nih.gov/pubmed/24428951

Nunes, L. M (2015). Importância do aleitamento materno na atualidade. Boletim Científico de Pediatria, 4(3):55-8. Acesso em 20 de abr de 2020. Disponível em:

https://www.sprs.com.br/sprs2013/bancoimg/160529234034bcped_v4_n3_a2.pdf

Pereira, A.S. et al. (2018). Metodologia da pesquisa científica. [e-book]. Santa Maria. Ed.

UAB/NTE/UFSM. Acesso em: 30 Abril 2020. Disponível em: 
https://repositorio.ufsm.br/bitstream/handle/1/15824/Lic_Computacao_Metodologia-

Pesquisa-Cientifica.pdf?sequence $=1$

Souza, S.A., Araújo, R.T., Teixeira, J.R.B., \& Mota, T.N. (2016). Aleitamento materno: fatores que influenciam o desmame precoce entre mães adolescentes. Revista de Enfermagem UFPE Online, 10(10):3806-13. Acesso em 20 de abr de 2020. Disponível em: https://periodicos.ufpe.br/revistas/revistaenfermagem/article/view/11446

Toryiama, Á. T. M., Fujimori, E., Palombo, C. N. T., Duarte, L. S., Borges, A. L. V., \& Chofakian, C. B. D. N. (2017). Aleitamento materno: o que mudou após uma década? Revista Latino-Americana de Enfermagem, 25. Acesso em 20 de abr de 2020. Disponível em: http://www.scielo.br/scielo.php?pid=S0104-11692017000100387\&script=sci_arttext\&tlng=pt

\section{Porcentagem de contribuição de cada autor no manuscrito}

Eyshila Marilia Almeida Rocha - 14,3\%

Lawanda Kelly Matias de Macedo - 14,3\%

Layla Valéria Araújo Borges - 14,3\%

Aline Maria da Costa Pinheiro - 14,3\%

Rosielly da Silva Santos - 14,3\%

Hayla Nunes da Conceição - 14,3\%

Joseneide Teixeira Câmara - 14,3\% 